\title{
Efeito da microbiota cecal e do Lactobacillus salivarius inoculados in ovo em aves desafiadas com Salmonella enterica sorovar Enteritidis
}

\author{
[Effect of cecal microflora and Lactobacillus salivarius in ovo administration used on chicken previously challenged \\ with Salmonella enterica serovar Enteritidis] \\ R.L. Andreatti Filho' ${ }^{1}$, A.S. Okamoto ${ }^{1}$, E.T. Lima ${ }^{1}$, P.R. Gratão ${ }^{1}$, S.R. DelBem ${ }^{2}$ \\ ${ }^{1}$ Faculdade de Medicina Veterinária e Zootecnia - UNESP \\ Distrito de Rubião Jr., s/n \\ 18618-000 - Botucatu, SP \\ ${ }^{2}$ Céu Azul Alimentos Ltda - Pereiras, SP
}

\begin{abstract}
RESUMO
Ovos embrionados provenientes de matrizes pesadas foram inoculados na câmara de ar com microbiota cecal total, microbiota cecal diluída e cultura de Lactobacillus salivarius, no $18^{\circ}$ dia de incubação. Dois dias após o nascimento, as aves foram desafiadas com Salmonella enterica sorovar Enteritidis (SE) e, cinco dias após o desafio, avaliou-se a presença da bactéria no fígado e ceco. O efeito de exclusão competitiva, após o desafio com SE, somente foi observado pela ausência da bactéria no fígado das aves tratadas in ovo com L. salivarius. A inoculação in ovo de microbiota cecal indefinida ou diluída não reduziu a colonização de SE no fígado e no ceco das aves, incluindo, neste último, também o tratamento com L. salivarius. Nenhum dos tratamentos in ovo determinou índice de eclodibilidade superior a $65 \%$.
\end{abstract}

Palavras-chave: galinha, Salmonella entérica, Lactobacillus salivarius, microbiota cecal, exclusão competitiva, in ovo

\begin{abstract}
Commercial 18-day-old incubating chicken embryos were inoculated with total or diluted cecal microbiota and Lactobacillus salivarius cultures directly into the inner air sac. Two days after hatching, the chicks were challenged with Salmonella enterica serovar Enteritidis (SE), and five days later the presence of bacteria in cecum and liver was evaluated. The competitive exclusion effect was determined by the search for SE in the liver of chicks treated in ovo with L. salivarius and challenged with SE. The in ovo inoculation of total or diluted cecal microbiota, in addition to the L. salivarius treatment did not significantly decrease the colonization of SE in liver and cecum. All treatments resulted in hatchability of $65 \%$ or less.
\end{abstract}

Keywords: chicken, Salmonella enterica, Lactobacillus salivarius, anaerobic cecal microflora, competitive exclusion, in ovo

\section{INTRODUÇÃO}

A infecção por Salmonella spp. em galinha pode ser reduzida pela colonização precoce do trato intestinal de pintos por bactérias da microbiota intestinal normal de aves adultas. O processo, conhecido como exclusão competitiva (EC), foi descrito por Nurmi e Rantala (1973) e é amplamente aceito nos dias atuais (Parra, 1994).

Em condições normais, os pintos recebem a microbiota intestinal principalmente das mães.

Recebido em 13 de abril de 2005

Aceito em 23 de março de 2006.

E-mail: andreatti@fmvz.unesp.br 
Em galinhas e perus, essa transferência de microrganismos é muito eficiente quando os recém-nascidos são criados em estreito contato com aves adultas. $\mathrm{Na}$ avicultura industrial, o contato entre pintos e aves adultas não ocorre, com o conseqüente retardo no desenvolvimento na ave jovem da microbiota intestinal protetora (Tortuero, 1973; Parra, 1994).

Em aves com microbiota estabelecida, Lactobacillus salivarius, Lactobacillus fermentum e Lactobacillus reuteri predominam no inglúvio e intestino delgado, enquanto $L$. acidophilus é encontrado no inglúvio, cloaca, duodeno, jejuno e cecos, apresentando funções benéficas contra bactérias patogênicas (Parra, 1994; Andreatti Filho e Sampaio, 1999).

Produtos de EC podem ser aplicados na superfície dos ovos embrionados de galinhas e perus para permitir o contato precoce do pinto recém-nascido com a microbiota própria das aves adultas e, assim, prevenir as eventuais contaminações do pinto por Salmonella spp. e outros patógenos entéricos (Cox et al., 1992). Cox et al. (1991) demonstraram que incubadoras comerciais são costumeiramente contaminadas com Salmonella spp., o que pode limitar a efetividade do tratamento posterior por meio de EC.

Sharma e Burmester (1982) foram os primeiros a utilizar o conceito da vacinação in ovo contra a doença de Marek. Posteriormente, utilizando a mesma técnica, Edens et al. (1997) demonstraram que o uso de $L$. reuteri induziu proteção em frangos e perus contra Salmonella enterica sorovar Typhimurium (SE). A via de administração in ovo é um método atraente de aplicação de produtos de EC, pois as aves já nasceriam com o trato intestinal colonizado por bactérias benéficas.

O objetivo do presente trabalho foi testar o efeito da administração in ovo de microbiota cecal e de L. salivarius na presença de $\mathrm{S} E$, verificando-se a sua presença no fígado e ceco dos pintos.

\section{MATERIAL E MÉTODOS}

Foram utilizados 80 ovos embrionados provenientes de um mesmo lote de matrizes pesadas da linhagem Ross. Os ovos foram distribuídos aleatoriamente em quatro grupos de
20 ovos, cada um correspondendo a um tratamento. No tratamento I, os ovos foram inoculados com microbiota cecal indefinida cultivada em anaerobiose contendo $5,0 \times 10^{7}$ unidades formadoras de colônia (UFC) $/ \mathrm{ml}$. No tratamento II, foi inoculada microbiota cecal indefinida diluída a $10^{-3}$ em salina fosfatada tamponada (PBS) na quantidade de $5,0 \times 10^{4} \mathrm{UFC} / \mathrm{ml}$. No tratamento III, inoculou-se cultura de $L$. salivarius contendo $1,5 \times 10^{7} \mathrm{UFC} / \mathrm{ml}$ e, no tratamento IV, os ovos foram inoculados com $0,2 \mathrm{ml}$ de PBS estéril.

A determinação dos inóculos da microbiota cecal foi feita por meio do plaqueamento de $0,1 \mathrm{ml}$ das suspensões em caldo tioglicolato e respectivas diluições decimais em PBS, em duplicata de ágar tioglicolato, cultivados em jarra de anaerobiose contendo o sistema Anaerobac-PROBAC, durante 24 horas a $40^{\circ} \mathrm{C}$. A determinação do inóculo de L. salivarius foi feita por meio de diluição decimal seriada do caldo DeManRugosa-Sharpe (MRS) em PBS e plaqueamento de $0,1 \mathrm{ml}$ dessas diluições em placas de Petri contendo ágar MRS, incubado em anaerobiose (Anaerobac-PROBAC) por 24 horas a $40^{\circ} \mathrm{C}$.

A microbiota foi preparada a partir do conteúdo cecal de três galinhas adultas specific pathogen free (SPF). Após o sacrifício das aves, estas foram necropsiadas assepticamente para retirada dos cecos, que foram triturados e imersos em $10 \mathrm{ml}$ de PBS, transferindo-se $1 \mathrm{ml}$ deste conteúdo para $10 \mathrm{ml}$ de caldo tioglicolato. Posteriormente, a cultura foi incubada a $37^{\circ} \mathrm{C}$ por 24 horas em condições de anaerobiose (AnaerobacPROBAC). Em seguida, alíquotas de $3 \mathrm{ml}$ desse caldo foram distribuídas em criotubos e congeladas em nitrogênio líquido para posterior utilização na inoculação dos ovos. A cultura de L. salivarius, previamente isolada de aves, foi obtida da bacterioteca do serviço de ornitopatologia da FMVZ-UNESP-Botucatu, ressuspensa em caldo MRS e incubada a $37^{\circ} \mathrm{C}$ por 24 horas em condições de anaerobiose (Anaerobac-PROBAC).

Os ovos foram incubados em incubadora comercial $^{1}$ com temperatura de $37,5^{\circ} \mathrm{C}$ e $30 \%$ de umidade relativa. No $18^{\circ}$ dia de incubação, após ovoscopia para determinar a posição da câmara de ar, os ovos foram desinfetados com álcool

${ }^{1}$ Céu Azul Alimentos Ltda - Pereiras - SP 
$70 \%$ e inoculados com $0,2 \mathrm{ml}$ do material de cada tratamento no centro da câmara de ar, utilizandose agulhas de $5 / 8$ (16mm). Em seguida, os ovos foram transferidos para um nascedouro $\operatorname{comercial}^{1}$ com temperatura de $36,8^{\circ} \mathrm{C}$ e $32 \%$ de umidade relativa.

Dois dias após a eclosão, os pintos foram desafiados com $S E$ isolada de fígado de matrizes pesadas e sorotipada pelo Instituto Adolfo Lutz SP, mantida na bacterioteca do laboratório de ornitopatologia da FMVZ em tubos de ensaio de $13 \times 100 \mathrm{~mm}$ contendo ágar nutriente, vedados com rolha de borracha e armazenados a temperatura entre $2-8^{\circ} \mathrm{C}$. Da cultura estoque isolou-se uma variante resistente ao ácido nalidíxico (Nal) e rifampicina (Rif), desenvolvida por meio de cultivos sucessivos em ágar verde brilhante (BGA) contendo $100 \mu \mathrm{g} / \mathrm{ml}$ de Nal e Rif (Weinack et al., 1982), para facilitar posterior enumeração bacteriana. Para uso, a bactéria foi semeada em caldo infusão de cérebro e coração (BHI) e incubada a $40^{\circ} \mathrm{C}$ por 12 horas. $\mathrm{O}$ número de UFC nos inóculos foi determinado por meio de diluições decimais em PBS com pH 7,2 .

Após o nascimento, as aves foram alojadas em gaiolas de metal, sob aquecimento. No segundo dia de vida, foram desafiadas por via intraesofagiana com $0,5 \mathrm{ml}$ de inóculo de SE contendo $9,0 \times 10^{3} \mathrm{UFC} / \mathrm{ml}$. Cinco dias após o desafio, as aves foram sacrificadas por deslocamento cervical. O fígado, retirado assepticamente, foi triturado individualmente em gral e suspenso em $20 \mathrm{ml}$ de PBS. A suspensão obtida foi diluída em escala decimal e titulada por plaqueamento de $0,1 \mathrm{ml}$ das diluições em duplicata de BGA contendo $100 \mu \mathrm{g} / \mathrm{ml}$ de Nal e Rif, cultivadas durante 24 horas a $40^{\circ} \mathrm{C}$. Os cecos foram removidos assepticamente e, com auxílio de suabe estéril, avaliou-se a colonização cecal por meio de cultivo direto em placas de Petri contendo BGA (Nal/Rif). A colonização foi avaliada pela intensidade de crescimento bacteriano nas placas para determinar a quantidade de UFC. A colonização cecal foi demonstrada por meio do seguinte critério: crescimento de 0,1 a $10 \mathrm{UFC}$, escore 1; de 11 a 50UFC, escore 2; de 51 a $100 \mathrm{UFC}$, escore 3 e acima de 100UFC, escore 4 (Weinack et al., 1981; Andreatti Filho et al., 1993).

Para comparação dos grupos em relação às variáveis UFC e escore relativo ao índice de colonização cecal usou-se o teste não paramétrico de Kruskal-Wallis (Zar, 1996).

\section{RESULTADOS E DISCUSSÃO}

A colonização do ceco das aves desafiadas com $\mathrm{SE}$, após inoculação in ovo de microbiota cecal indefinida (MCI), microbiota cecal indefinida diluída (MCID) e L. salivarius, está na Tab. 1. Em todas as aves, independente do tratamento, foi observada a presença de SE no ceco. Também em relação ao escore de colonização cecal não houve diferença significativa entre os tratamentos.

Em relação à presença de $\mathrm{SE}$ no fígado, observou-se diferença na quantidade de UFC entre o tratamento com L. salivarius e os demais (Tab. 2). No tratamento com MCI, 18\% das aves apresentaram-se positivas para SE no fígado, e nos tratamentos com MCID e no controle, os valores foram $58 \%$ e $46 \%$, respectivamente. Não foi detectada SE no fígado das aves tratadas com L. salivarius, resultado significativamente distinto dos valores medianos de UFC da bactéria nos demais tratamentos.

Tabela 1. Colonização de Salmonella Enteritidis (SE) nos cecos de aves desafiadas* via intraesofagiana, após inoculação in ovo de microbiota cecal indefinida (MCI), microbiota cecal indefinida diluída (MCID) e Lactobacillus salivarius

\begin{tabular}{lcc}
\hline Tratamento & Aves positivas / aves desafiadas & Mediana** \\
\hline MCI $\left(5 \times 10^{7} \mathrm{UFC} / \mathrm{ml}\right)$ & $11 / 11$ & 2,0 \\
$\mathrm{MCID}\left(5 \times 10^{4} \mathrm{UFC} / \mathrm{ml}\right)$ & $12 / 12$ & 4,0 \\
L. salivarius $\left(1,5 \times 10^{7} \mathrm{UFC} / \mathrm{ml}\right)$ & $12 / 12$ & 2,5 \\
Controle $(\mathrm{PBS})$ & $13 / 13$ & 3,0 \\
\hline
\end{tabular}

* $9 \times 10^{3}$ unidades formadoras de colônia (UFC)/ml de SE ácido nalidíxico/rifampicina.

**Valores medianos (percentis $\mathrm{P}_{25}$ e $\mathrm{P}_{75}$ ) de escore de colonização para cada tratamento. Resultados expressos em escore de colonização cecal: 1 a 10UFC (1); 11 a $50 \mathrm{UFC}$ (2); 51 a 100UFC (3) e acima de 100UFC (4); (P=0,21).

Não se observou diferença entre os tratamentos. 
Tabela 2. Presença de Salmonella Enteritidis no fígado de aves desafiadas* via intraesofagiana, após inoculação in ovo de microbiota cecal indefinida (MCI), microbiota cecal indefinida diluída (MCID) e Lactobacillus salivarius

\begin{tabular}{lcc}
\hline Tratamento & Aves positivas / aves desafiadas & Mediana** \\
\hline MCI $\left(5 \times 10^{7} \mathrm{UFC} / \mathrm{ml}\right)$ & $2 / 11$ & $3,0 \mathrm{a}$ \\
$\mathrm{MCID}\left(5 \times 10^{4} \mathrm{UFC} / \mathrm{ml}\right)$ & $7 / 12$ & $3,5 \mathrm{a}$ \\
L. salivarius $\left(1,5 \times 10^{7} \mathrm{UFC} / \mathrm{ml}\right)$ & $0 / 12$ & $0,0 \mathrm{~b}$ \\
Controle (PBS) & $6 / 13$ & $4,5 \mathrm{a}$ \\
\hline
\end{tabular}

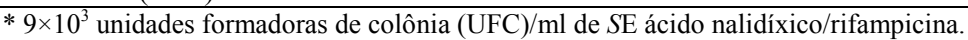

** Valores medianos (percentis $\mathrm{P}_{25}$ e $\mathrm{P}_{75}$ ) de UFC para cada tratamento. Resultados em logarítimo decimal $(\mathrm{UFC} / \mathrm{fígado})$; $(\mathrm{P}<0,05)$.

Letras distintas na coluna indicam diferença significativa entre os tratamentos.

Cox et al. (1992), ao administrarem microbiota cecal indefinida na câmara de ar de ovos de galinha, observaram redução na quantidade de aves positivas após desafio com $10^{3} \mathrm{UFC} /$ ave de $S$. Typhimurium, indicando ser possível proteger aves contra Salmonella, ainda durante o período de incubação. Neste trabalho, ao se desafiar as aves com $9 \times 10^{3} \mathrm{UFC} /$ ave de SE, observou-se redução significativa na quantidade de aves positivas, apenas nas tratadas com $L$. salivarius. Este resultado assemelha-se ao observado por Pascual et al. (1999), os quais demonstraram que o L. salivarius, administrado via oral reduziu significativamente a quantidade de aves positivas após desafio com SE.

O efeito da inoculação in ovo de MCI, MCID e L. salivarius sobre a eclodibilidade de ovos de galinha está na Tab. 3. A eclodibilidade variou de 55 a $65 \%$, incluindo a do tratamento controle. Não houve variação significativa entre os tratamentos. Cox et al. (1992), ao administrarem microbiota cecal não diluída na câmara de ar dos ovos, obtiveram $56 \%$ de eclodibilidade, muito próximo do observado neste experimento, em que se obtiveram $55 \%$ de eclodibilidade. Hulet e Meijerhof (1997) observaram redução na eclodibilidade, quando ovos de galinha foram inoculados com cultura de exclusão competitiva. Edens et al. (1997) observaram que L. reuteri não afetou a eclodibilidade, além e propiciar aumento na altura das vilosidades e na profundidade das criptas do intestino das aves. Neste trabalho, L. salivarius possibilitou eclodibilidade de $60 \%$. Entretanto, estes resultados estão aquém dos índices de eclodibilidade obtidos comercialmente.

Tabela 3. Efeito da inoculação in ovo de microbiota cecal indefinida (MCI), microbiota cecal indefinida diluída (MCID) e Lactobacillus salivarius sobre a eclodibilidade de ovos de galinha

\begin{tabular}{lcc}
\hline Tratamento & Eclodibilidade* & $\%$ \\
\hline MCI $\left(5 \times 10^{7} \mathrm{UFC} / \mathrm{ml}\right)$ & $11 / 20$ & 55 \\
MCID $\left(5 \times 10^{4} \mathrm{UFC} / \mathrm{ml}\right)$ & $12 / 20$ & 60 \\
L. salivarius $\left(1,5 \times 10^{7}\right.$ & $12 / 20$ & 60 \\
UFC $/ \mathrm{ml})$ & & \\
Controle (PBS) & $13 / 20$ & 65 \\
\hline
\end{tabular}

* Número de aves nascidas / número de ovos férteis incubados.

Não se observou diferença entre os tratamentos.

A ação de produtos de exclusão competitiva foi constatada em diversos trabalhos, através da redução da colonização por Salmonella spp. em aves (Bailey et al., 1988; Cox et al., 1992; Andreatti Filho et al., 2003). Com o intuito de se antecipar à contaminação por Salmonella spp., alternativas à administração desses produtos logo após o nascimento, como o uso in ovo, estão sendo estudadas (Cox et al., 1992; Edens et al., 1997; Hulet e Meijerhof, 1997). Neste trabalho, assim como na literatura consultada, verificou-se que o uso in ovo de produtos de exclusão competitiva necessita de maiores esclarecimentos para sua validação científica, incluindo a viabilidade econômica.

\section{CONCLUSÕES}

A inoculação in ovo com Lactobacillus salivarius preveniu a infecção hepática de pintos por Salmonella Enteritidis. A inoculação de microbiota cecal indefinida ou diluída não reduziu a colonização de SE no fígado e nos ceco das aves. 


\section{REFERÊNCIAS BIBLIOGRÁFICAS}

ANDREATTI FILHO, R.L.; SAMPAIO, H.M. Probióticos e prebióticos: realidade na avicultura industrial moderna. Rev. Educ. Contin. CRMV$S P$, v.2, p.59-71, 1999.

ANDREATTI FILHO, R.L.; SAMPAIO, H.M.; BARROS, M.R. et al. Use of cecal microflora cultured under aerobic or anaerobic conditions in the control of experimental infection of chicks with Salmonella Enteritidis. Vet. Microbiol., v.92, p.237-244, 2003.

ANDREATTI FILHO, R.L.; SILVA, E.N.; BALEN, L. Efeito da via de inoculação na patogenicidade de amostras patogênica e apatogênica de Escherichia coli em galinha. Arq. Bras. Med. Vet. Zootec., v.45, p.475-486, 1993.

BAILEY, J.S.; BLANKENSHIP, L.C.; STERN, N.J. et al. Effect of anticoccidial and antimicrobial feed additives on prevention of Salmonella colonization of chicks treated with anaerobic cultures of chicken feces. Avian Dis., v.32, p.324-329, 1988.

COX, N.A.; BAILEY, J.S.; BLANKENSHIP, L.C. et al. Research Note: In ovo administration of a competitive exclusion culture treatment to broiler embryos. Poult. Sci., v.71, p.1781-1784, 1992.

COX, N.A.; BAILEY, J.S.; MAULDIN, J.M. et al. Extent of salmonellae contamination in breeder hatcheries. Poult. Sci., v.70, p.416-418, 1991.

EDENS, F.W.; PARKHURST, C.R.; CASAS, I.A. et al. Principles of ex ovo competitive exclusion and in ovo administration of Lactobacillus reuteri. Poult. Sci., v.76, p.179196, 1997.
HULET, R.M.; MEIJERHOF, R. In ovo injection of competitive exclusion culture in broiler hatching eggs. J. Appl .Poult. Res., v.6, p.260266, 1997.

NURMI, E; RANTALA, M. New aspects of Salmonella infection in broiler production. Nature, v.241, p.210, 1973.

PARRA, F.E. Exclusion competitive in Salmonelosis: Revision. In: SEMINÁRIO INTERNACIONAL DE PATOLOGIA AVIAR, 1994, Athens. Anais... Athens, 1994. p.433-469.

PASCUAL, M.; HUGAS, M.; IGNACIO BADIOLA, J. et al. Lactobacillus salivarius CTC2197 prevents Salmonella enteritidis colonization in chickens. Appl. Environ. Microbiol., v.65, p.4981-4986, 1999.

SHARMA, J.M.; BURMESTER, B.R. Resistance to Marek's Disease at hatching in chickens vaccinated as embryos with the turkey herpesvirus. Avian Dis., v.26, p.134-149, 1982.

TORTUERO, F. Influence of the implantation of Lactobacillus acidophilus in chicks on the growth, feed conversion, malabsorption of fats sindrome and intestinal flora. Poult. Sci., v.52, p.197-203, 1973.

WEINACK, O.M; SNOEYENBOS, G.H.; SMYSER, C.F. et al. Competitive exclusion of intestinal colonization of Escherichia coli in chicks. Avian Dis., v.25, p.696-705, 1981.

WEINACK, O.M.; SNOEYENBOS, G.H.; SMYSER, C.F. et al. Reciprocal competitive exclusion of Salmonella and Escherichia coli by native intestinal microflora of the chicken and turkey. Avian Dis., v.26, p.585-595, 1982.

ZAR, J.H. Biostatistical analysis. New Jersey: Prentice Hall, 1996. 718p. 